\title{
Lusioersily
}

\section{The integration of triggered drug delivery with real time quantification using FRET; creating a super 'smart' drug delivery system}

Aibani, N., Fontoura da Costa, P., Masterson, J., Marino, N., Raymo, F. M., Callan, J. F., \& Callan, B. (2017). The integration of triggered drug delivery with real time quantification using FRET; creating a super 'smart' drug delivery system. Journal of Controlled Release, 264, 136-144. https://doi.org/10.1016/j.jconrel.2017.08.013

Link to publication record in Ulster University Research Portal

Published in:

Journal of Controlled Release

Publication Status:

Published (in print/issue): 28/10/2017

DOI:

10.1016/j.jconrel.2017.08.013

Document Version

Author Accepted version

\section{General rights}

Copyright for the publications made accessible via Ulster University's Research Portal is retained by the author(s) and / or other copyright owners and it is a condition of accessing these publications that users recognise and abide by the legal requirements associated with these rights.

\section{Take down policy}

The Research Portal is Ulster University's institutional repository that provides access to Ulster's research outputs. Every effort has been made to ensure that content in the Research Portal does not infringe any person's rights, or applicable UK laws. If you discover content in the Research Portal that you believe breaches copyright or violates any law, please contact pure-support@ulster.ac.uk. 


\section{Title:}

The integration of triggered drug delivery with real time quantification using FRET; creating a super 'smart' drug delivery system.

\section{Authors:}

Noorjahan Aibania, Paola Fontoura da Costa $^{\mathrm{a}}$, Jodie Masterson ${ }^{\mathrm{a}}$, Nino Marino ${ }^{\mathrm{a}}$, Francisco M. Raymo John Callanª and Bridgeen Callan*a

a. School of Pharmacy and Pharmaceutical Sciences, University of Ulster, Coleraine, BT52 1SA, Northern Ireland, United Kingdom

b. Laboratory for Molecular Photonics, Department of Chemistry, University of Miami, 1301 Memorial Drive, Coral Gables, Florida, 33146-0431

\section{Abstract}

The ability to control drug release at a specific physiological target enables the possibility of an enhanced therapeutic effect with reduced off-target toxic side effects. The discipline of controlled drug release has grown to include most areas of medicine with examples in the literature of targeted drug delivery to the majority of organs within the human body. In addition, a variety of external stimuli used to meditate the drug release process have also been investigated. Nonetheless, the concurrent real time monitoring of drug release has not been widely studied. In this manuscript, we present a novel micellar drug delivery system that is not only capable of releasing its cargo when stimulated by light but also provides a real time analysis of the amount of cargo remaining. Controlled drug release from the delivery system was mediated by physicochemical changes of a spiropyran-merocyanine photochromic dyad, while drug quantification was enabled using a Förster Resonance Energy Transfer (FRET) relationship between the photochrome and a co-encapsulated BODIPY fluorophore. 
The percentage of drug released from the delivery system was significantly greater (24\%) when exposed to light irradiation compared to an analogous control maintained in the dark (5\%). Furthermore, the fluorescence read-out capability also enabled the drugrelease process to be followed in living cells with a significantly reduced fluorescence emission observed for those cells incubated with the delivery system and exposed to light irradiation compared to control cells maintained in the dark. Combined, these results highlight the utility of this approach to theranostic drug delivery with the potential of light-triggered released together with a fluorescence read-out to enable quantification of the drug release process.

Key words: Real-time analysis; photo-transformation; FRET; hydrophobic drug delivery; micelles; stimuli responsive

\section{Introduction}

In order for a drug to produce a therapeutic effect, it must not only reach the site of action but also have the correct physicochemical properties to allow it to be absorbed at an appropriate concentration. In the past few decades, smart drug delivery systems (DDS) have evolved to deliver an appropriate dose to meet the patients needs [1]. Delivering the drug at a controlled rate, triggered drug release and targeted drug delivery are some methods that have been extensively investigated. Some examples of such systems include the development of biopharmaceutical systems capable of interacting with intracellular components that respond as a direct result to environmental stimuli [2] and nanoparticles that specifically bind to tumour cells using receptor targeted systems [3] [4]. Among these, triggered release plays a substantial role on controlling timing and location of drug release, since it can be induced by several external stimuli acting on the intracellular vehicles response [5]. Examples of stimuli used to facilitate drug release are temperature [6], $\mathrm{pH}$ [7], magnetic field [8], electric field [9], ultrasound [10], enzymatic activity [11] and light [12].

Light responsive drug release is an attractive mechanism because of the ability to control the spatial and temporal triggering of the release process [13]. Numerous 
examples of photochromic materials capable of transforming under the influence of activating radiation have been explored over recent years [14]. However, the photo activating ability of Spiropyran compounds was recognised as early as the1920's [15]. Spiropyran can undergo a reversible response to light and chemical stimulations. The closed ring stable state of Spiropyran (a) can be converted to its open form, Merocyanine (b), when irradiated with UV light, which is converted back into its original state when irradiated with visible light (Figure 1).

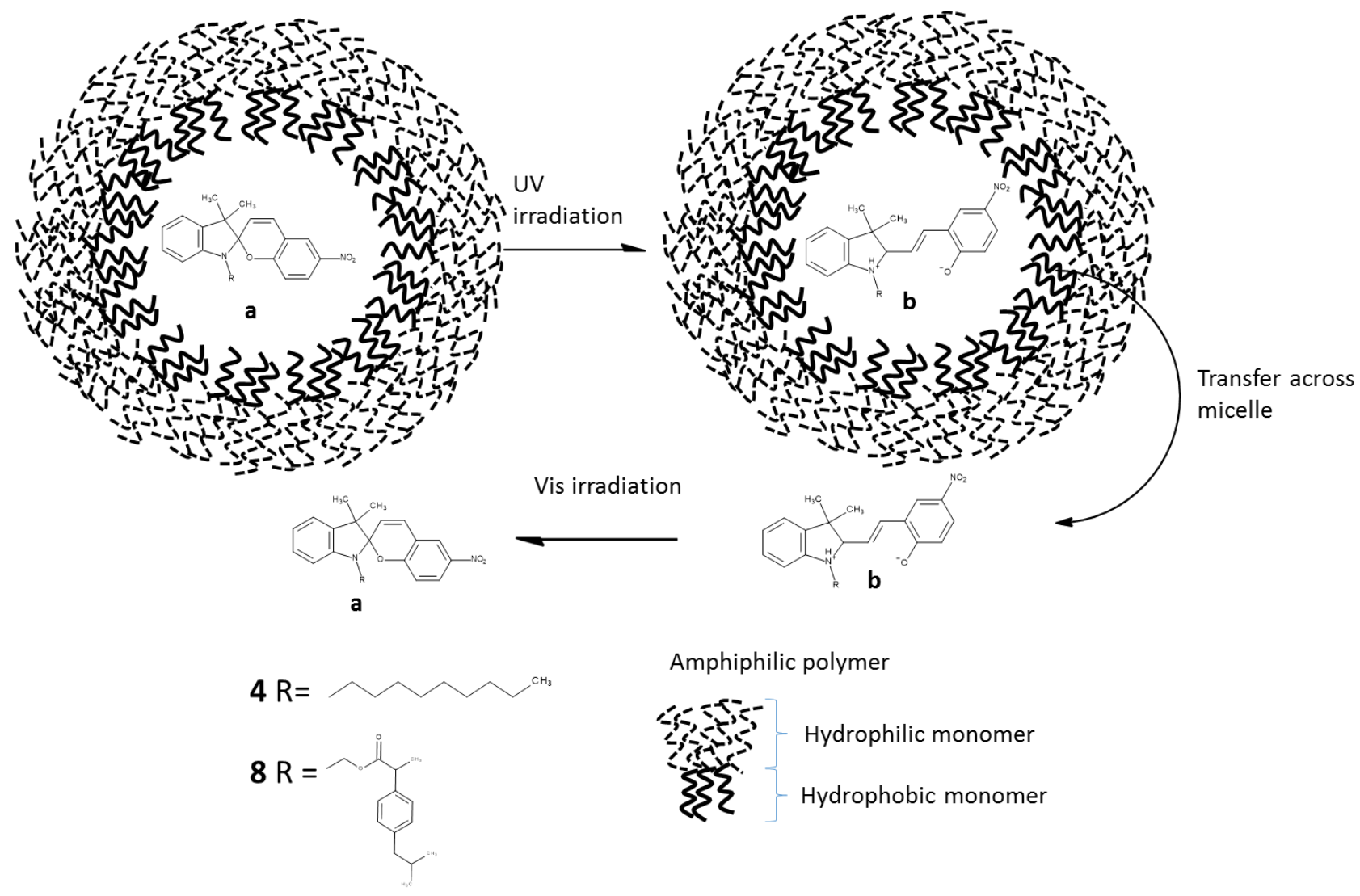

Figure 1. Illustration of the phototranformation of spiropyran (a) to its merocyanine (b) counterpart and subsequent movement within the micellar environment before transformation back under visible irradiation

This simple photochromic transformation has found many applications ranging from molecular sensors [16] to DNA-based logic operations [17] and bioimaging [18]. Here, we exploit differences in the hydrophobic/hydrophilic balance between the two isomers to mediate drug release from a micellar based delivery system. The spiropyran form, with its hydrophobic four-ring system preferentially favours a non-polar environment 
whereas its open ring zwitterionic merocyanine counterpart prefers a more hydrophilic environment.

In addition to the triggered delivery mechanism there are also a number of considerations to make when selecting the type of DDS. More than $40 \%$ of newly discovered drugs have little or no aqueous solubility (as determined by the Biopharmaceutical Classification System): 90 \% of drugs approved since 1995 have poor aqueous solubility, poor permeability or both [19]. The delivery of hydrophobic drugs can be achieved in a number of ways. For example, a pro drug of the active compound may be prepared to catabolize to the original drug. Alternatively, a specific functional group can be altered to create a synthetic analogue with more appropriate hydrophilicity, or the compound may be formulated in such a way as to enable delivery by enteric coating for oral delivery or by an alternative method such as rectal or intravenous administration. All of these approaches have proven successful in delivering hydrophobic compounds. However, these approaches can often lead to enhanced first pass effects and thus the requirement for higher dosage or enhanced expense or, depending on the dosage form, poor patient compliance.

An alternative and successful method for the delivery of hydrophobic drugs is the use of polymeric drug delivery systems. These DDSs can be formulated as, micelles [20], liposomes [21], nanofibers [22], dendrimers [23], colloids [24] or carbon nanotubes [25] with the majority of them falling into the category of nanoparticle drug delivery vehicles. It has been suggested that the polymeric nano carriers can become concentrated preferentially in tumors, inflammatory sites, and at antigen sampling sites by virtue of the enhanced permeability and retention (EPR) effect of the vasculature [26]. Once accumulated at the site, these polymeric drug delivery vehicles can act as a drug depot, providing a source of API to be released as and when required. This leads to enhanced bioavailability, sustained/controlled release and decreased toxicity caused by potential burst release of the API. There are numerous examples where polymeric compounds are shown to enhance drug delivery [27]. Among these systems Polyethylene glycol (PEG) is frequently used as a polymeric component. We have previously developed a PEG-micellar DDS and determined the size of our PEG copolymers to have an average 
hydrodynamic diameter of $26 \mathrm{~nm}$ [18]. As a direct result of their size, these micelles can navigate through the endothelium in inflammatory sites, epithelium tumors or penetrate micro capillaries, allowing for uptake by a variety of cell types. We have previously shown these micelles to efficiently cross the cell membrane of Chinese hamster ovarian cells and distribute themselves in the cytosol.

Finally, the ability to quantitatively monitor the amount of drug release, from a DDS in real time using a simple but effective approach is an essential companion in the advance towards second-generation health care. To this end, there have been a number of examples where mesoporous silica nanoparticles (MSN) have been used as a cage for drug delivery with the drug co-incorporated alongside a photochromic compound [28], an oligonucleotide containing a recognition element [29] or a redox active FRET pair [30] so that the system operates like a molecular valve. In each case, the drug was prevented from exiting the pores of the NP due to the large bulky groups surrounding the MSN. On application of external stimuli, the outer layer (valve) was disrupted and the inner cargo released from the MSN. In addition to the triggered release, a Förster Resonance Energy Transfer (FRET) mechanism was utilised to enable real time monitoring of drug release.

In this manuscript, an alternative approach has been developed that combines a triggered release of hydrophobic drugs encapsulated within a polymeric micellar drug delivery system with real time analysis through molecular communication. This was achieved using a FRET mechanism whereby a FRET pair was contained within the hydrophobic interior of a self-forming amphiphilic micelle. Upon application of an external UV light trigger, one of the FRET pair, a Spiropyran moiety, undergoes a photo transformation to the more hydrophilic merocyanine isomer and transcends the micellar membrane into the aqueous external environment. The other half of the FRET pair, a hydrophobic bodipy fluorochrome, remains within the non-polar environment of the micelle. Thus, release of the merocyanine isomer from the micelle modulates the donoracceptor energy transfer process enabling the release process to be followed by fluorescence spectroscopy, illustrated in Figure 2. A decrease in the quenching ability 
of the merocyanine for the bodipy emission is observed relative to the amount of merocyanine remaining within the micellar structure.

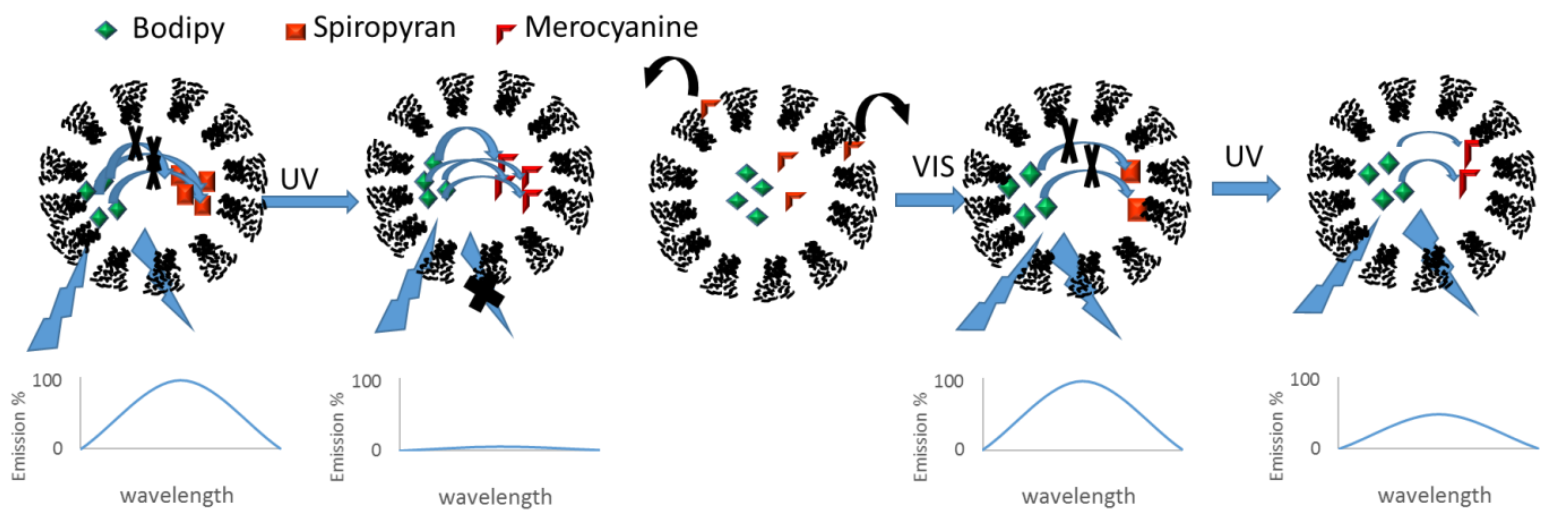

Figure 2. Schematic representation of the UV triggered release caused by the photoisomerism of Spiropyran to the zwitterionic Merocyanine transcending the amphiphilic micelle and concomitant quantification using FRET with the simulated emission of the Bodipy donor moiety.

Indeed, the scope of this approach can be further extended by conjugating an Active Pharmaceutical Ingredient (API) onto the Spiropyran isomer enabling its release to be controlled and monitored in real time. To illustrate this, we have attached ibuprofen to spiropyran using an ester linkage, determined the release of this conjugated ibuprofenspiropyran compound from the micelle upon UV light irradiation and compared these results to the release of unmodified spiropyran from the micelle.

\section{Materials and Methods}

\subsection{Materials}

All reagents and solvents were purchased from Sigma-Aldrich and used without further purification. 2,3,3-trimethylindolenine 98\%, 1-bromodecane 98\%, 2-hydroxy-5nitrobenzaldehyde 98\%, Piperidine $\geq 99.5 \%$, 2-bromoethanol 95\%, Potassium Hydroxide $85 \% \mathrm{KOH}$ Basis, Triethylamine $\geq 99 \%$, Boron Trifluoride $\geq 99.5 \%$, Trifluoroacetic Acid 99\%, 2,3-Dichloro-5,6-dicyano-p-benzoquinone 98\%, 4-Formylbenzoic acid 97\%, 2,4Dimethylpyrrole $97 \%$, Phosphate Buffered Saline Tablets, Dialysis tubing cellulose membrane flat width $10 \mathrm{~mm}$, Ibuprofen, 4-(dimethylamino)pyridine,

$\mathrm{N}, \mathrm{N}^{\prime}-$ 
Dicyclohexylcarbodiimide, Chloroform, Acetonitrile, Ethanol, Dichloromethane, Diethyl Ether, Hexane, Ethyl Acetate, Tetrahydrofuran.

\subsection{Synthesis of compounds}

The synthesis of hydrophobic spiropyran 1'-decyl-3',3'-dimethyl-6-nitro-spiro[chromene2,2'-indol-1-ium] (HSP) (4) has been previously described [18].

\subsubsection{Synthesis of (10-(4-(decylcarbamoyl)phenyl)-5,5-difluoro-1,3,7,9-tetramethyl- 5H-dipyrrolo[1,2-c:2',1'-f][1,3,2]diazaborinin-4-ium-5-uide) (3)}

Compound $\mathbf{3}$ was synthesized following a two-step procedure as detailed below.

Step 1: Synthesis of (10-(4-carboxyphenyl)-5,5-difluoro-1,3,7,9-tetramethyl-5Hdipyrrolo[1,2-c:2',1'-f][1,3,2]diazaborinin-4-ium-5-uide) (1) (S1)

To a solution of 4-formylbenzoic acid $(0.5 \mathrm{~g}, 3.3 \mathrm{mmol})$ and 2, 4-dimethylpyrrole $(0.69 \mathrm{~g}$, $7.3 \mathrm{mmol})$ in THF $(90 \mathrm{~mL})$ was added several drops of trifluoroacetic acid. The mixture was stirred at ambient temperature overnight, then a solution of 2,3-dichloro-5,6dicyano-p-benzoquinone $(0.75 \mathrm{~g}, 3.3 \mathrm{mmol})$ in THF $(120 \mathrm{~mL})$ was added. The mixture was stirred continuously for another $4 \mathrm{~h}$. After the addition of triethylamine $(18 \mathrm{~mL}, 0.13$ $\mathrm{mol}), \mathrm{BF}_{3} \cdot \mathrm{OEt}_{2}(18 \mathrm{~mL}, 0.15 \mathrm{~mol}$ ) was added dropwise to the mixture, which was cooled in an ice-water bath. The mixture was kept stirring at ambient temperature overnight, then filtered through a celite pad. The residue was washed with $\mathrm{CH}_{2} \mathrm{Cl}_{2}$ (ca. $50 \mathrm{~mL}$ ), then the combined filtrate was rotary evaporated to dryness. The residue was redissolved in $\mathrm{CH}_{2} \mathrm{Cl}_{2}(100 \mathrm{~mL})$ and the solution was washed with $5 \%$ aqueous $\mathrm{NaHCO}_{3}$ solution $(100 \mathrm{~mL})$ followed with water $(100 \mathrm{~mL} \times 2)$. The organic portion was dried over anhydrous $\mathrm{MgSO}_{4}$, then evaporated in vacuo. The crude product was purified by silica gel column chromatography using $\mathrm{CH}_{2} \mathrm{Cl}_{2} / \mathrm{MeOH} 99 / 1$ as the eluent to give 1 as an red solid $(0.615 \mathrm{~g}, 51 \%)(\mathrm{S} 2)$.

Step 2: Synthesis of compound 3 (Scheme 1)

A mixture of 1 (127 mg, $0.34 \mathrm{mmol})$, dodecylamine 2 (45 mg, $0.28 \mathrm{mmol})$, EDC (110 $\mathrm{mg}, 0.57 \mathrm{mmol}$ ), and DMAP (7 mg, $0.056 \mathrm{mmol}$ ) was dissolved in $20 \mathrm{~mL}$ of $\mathrm{CH}_{2} \mathrm{Cl}_{2}$. After stirring at $27^{\circ} \mathrm{C}$ for $1 \mathrm{~h}$ in the dark the solvent was removed under vacuum. The 
obtained crude product was purified by column chromatography (hexane/EtOAc 1:1) to give $160 \mathrm{mg}$ of 3 as a orange oil (yield $91 \%) .{ }^{1} \mathrm{H} \mathrm{NMR}\left(\mathrm{CDCl}_{3}, 500 \mathrm{MHz}\right): \delta=7.91$ (d, J = $8 \mathrm{~Hz}, 2 \mathrm{H}$ ), 7.39 (d, J = $8 \mathrm{~Hz}, 2 \mathrm{H}$ ), 6.18 (br s, 1H), 5.98 (s, 2H), 3.49 (t, J = $6 \mathrm{~Hz}, 2 \mathrm{H}$ ), $2.55(\mathrm{~s}, 6 \mathrm{H}), 1.65(\mathrm{~m}, 2 \mathrm{H}), 1.4-1.2(\mathrm{~m}, 14 \mathrm{H}), 1.35(\mathrm{~s}, 6 \mathrm{H}), 0.87$ (t, J = $6.5 \mathrm{~Hz}, 3 \mathrm{H})$; ESIMS: m/z 506 [M-1]-.

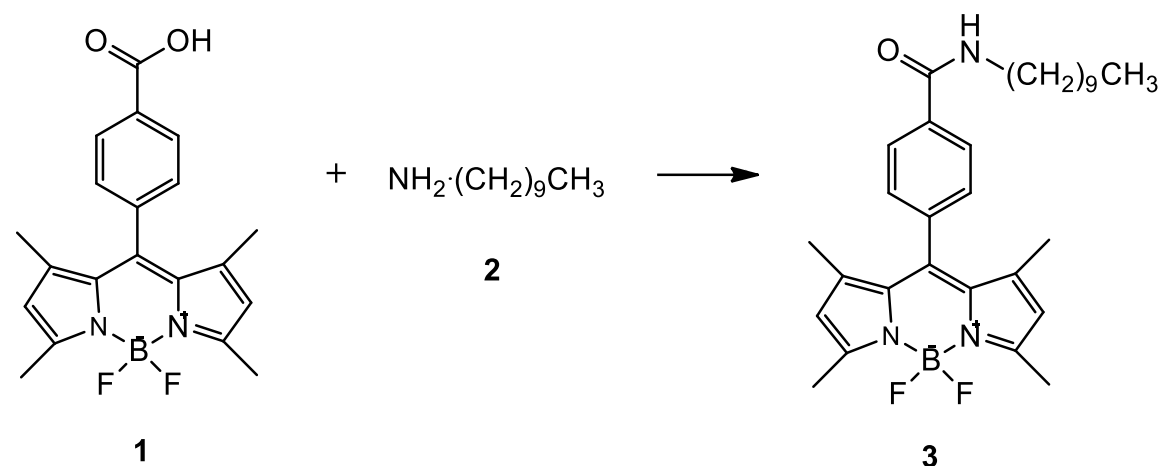

Scheme 1. Amidation of Bodipy compound 1 to increase the hydrophobicity of compound $\mathbf{3}$

2.3.2 Synthesis of Spiropyran compound 2-(3',3'-dimethyl-6-nitro-spiro[chromene2,2'-indol-1-ium]-1'-yl)ethyl 2-(4-isobutylphenyl)propanoate (8)

The synthesis of compound 8 (SP-IB) was a two-step process. The intermediate compound 2-(3',3'-dimethyl-6-nitrospiro[chromene-2,2'-indolin]-1'-yl)ethanol (6) was prepared following a literature procedure [31] (S3). The SP-IB was synthesized by a modified method from Baumann et. al. 2013 [32]. Synthesis of SP-IB 8 is detailed in Scheme 2. A mixture of 6 (100 mg, $0.28 \mathrm{mmol})$, Ibuprofen 7 (70 mg, $0.34 \mathrm{mmol})$, EDC (108 mg, $0.56 \mathrm{mmol}$ ), and DMAP (7 mg, $0.056 \mathrm{mmol}$ ) was dissolved in $20 \mathrm{~mL}$ of $\mathrm{CH}_{2} \mathrm{Cl}_{2}$. After stirring at room temperature for $1 \mathrm{~h}$ in dark, the purple solution becomes colorless and solvent was removed under vacuum. The obtained crude product was purified by column chromatography (hexane/EtOAc 4:1) to give $145 \mathrm{mg}$ of 8 as a green oil (yield 94\%). ${ }^{1} \mathrm{H}$ NMR $\left(\mathrm{CDCl}_{3}, 500 \mathrm{MHz}\right): \delta=7.99-7.94(\mathrm{~m}, 2 \mathrm{H}), 7.18(\mathrm{t}, \mathrm{J}=7.0 \mathrm{~Hz}, 1 \mathrm{H}), 7.14-$ $7.12(\mathrm{~m}, 2 \mathrm{H}), 7.07-7.06(\mathrm{~m}, 3 \mathrm{H}), 6.89(\mathrm{t}, \mathrm{J}=7.0 \mathrm{~Hz}, 1 \mathrm{H}), 6.79-6.66(\mathrm{~m}, 2 \mathrm{H}), 6.26(\mathrm{~d}, \mathrm{~J}=$ $6.5 \mathrm{~Hz}, 1 \mathrm{H}), 5.62(\mathrm{t}, \mathrm{J}=11.0 \mathrm{~Hz}, 1 \mathrm{H}), 4.22(\mathrm{~m}, 2 \mathrm{H}), 3.63(\mathrm{~m}, 1 \mathrm{H}), 3.45-3.31(\mathrm{~m}, 2 \mathrm{H})$, $2.44(\mathrm{t}, \mathrm{J}=6.0 \mathrm{~Hz}, 2 \mathrm{H}), 1.83(\mathrm{~m}, 1 \mathrm{H}), 1.45$ (dd, J = $21.0 \mathrm{~Hz}, \mathrm{~J}=7.0 \mathrm{~Hz}, 3 \mathrm{H}), 1.23$ (s, $3 \mathrm{H}), 1.06(\mathrm{~d}, \mathrm{~J}=22.0 \mathrm{~Hz}, 3 \mathrm{H}), 0.90(\mathrm{~d}, \mathrm{~J}=6.5 \mathrm{~Hz}, 6 \mathrm{H})$; ESIMS: m/z $541[\mathrm{M}+\mathrm{H}]+$. 


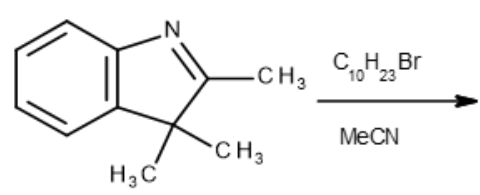

$\Delta 24 \mathrm{~h}$
$\mathrm{MeCN}$
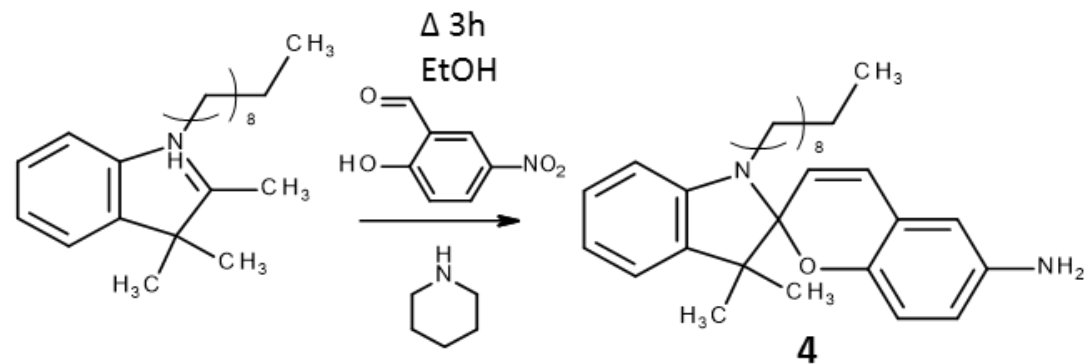

4

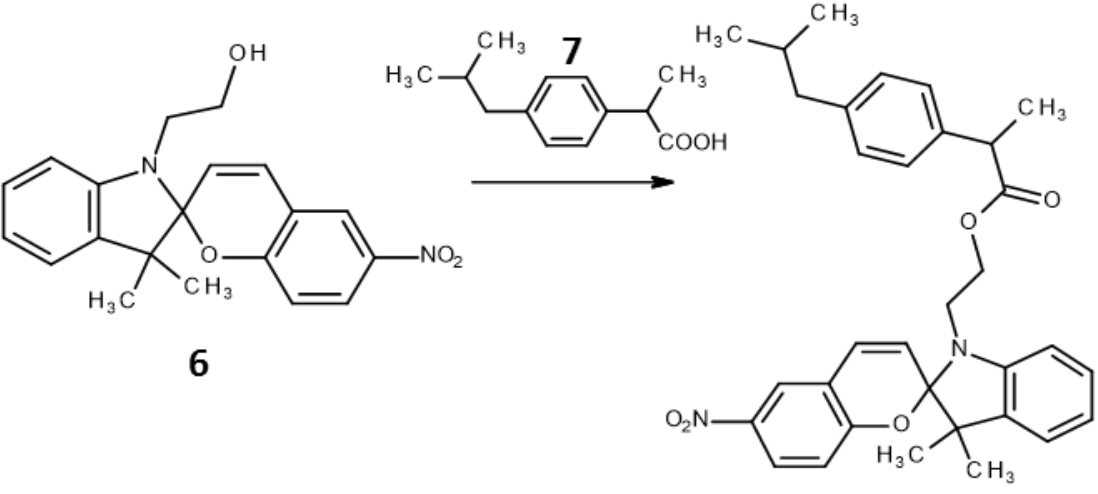

8

Scheme 2. Synthesis of Spiropyran compounds hydrophobic spiropyran (HSP) (4) and lbuprofen spiropyran (IBSP) (8).

\subsection{Preparation and characterisation of micelles}

The synthesis of the random co-polymer has been extensively described previously by the authors as both a hydrophobic [18] and hydrophilic [33] drug carrier and was prepared without further modification. It was comprised of two monomers (polyethylene glycol (PEG) (Mn 500) and a decyl chain (C10)) both containing a methacrylate functional group and polymerized using a free radical initiator in a 5: 3 molar ratio of PEG:C10 (scheme displayed in S5). The polymer has previously been determined to be biocompatible with negligible toxicity at the concentrations used. Micelles were prepared by evaporating the desired amount of polymer in $\mathrm{CHCl}_{3}$ in a round bottom flask along with $\mathbf{3}$ and $\mathbf{4}$ or $\mathbf{8}$ to form a thin film. The resultant film was hydrated with PBS to form the micelles. Micelle size, polydispersity index and zeta potential was analysed by dynamic light scattering using a Malvern Nano-ZS Zeta sizer. Particle morphology was observed by scanning electron microscopy (SEM) at high vacuum mode using $\mathrm{FEl}$ 
Quanta ESEM. A particle suspension was air dried for 24 hours on stainless steel stubs and further coated with ultra-thin Gold/Palladium layer at $18 \mathrm{~mA}$ for 3 minutes using Polaron Equipment Ltd E5100 Sputter coater and observed.

\subsection{Evaluation of phototransformation of $4 a$ to $4 b$}

$0.5 \mathrm{~mL}^{4 a}\left(0.1 \mathrm{mg} \mathrm{mL}^{-1}\right)$ was added to $0.6 \mathrm{~mL}$ polymer $\left(2.5 \mathrm{mg} \mathrm{mL}^{-1}\right)$ and evaporated into a thin film and hydrated with $3 \mathrm{~mL}$ PBS to form micelles. These samples were irradiated from a fixed distance of $4 \mathrm{cms}$ at $365 \mathrm{~nm}\left(0.4 \mathrm{~mW} \mathrm{~cm}{ }^{-2}\right)$ with a Mineralight UVGL-25 lamp (UVP 95-0006-03 Model UVL-56 6 Watt). The UV-Vis spectra was recorded using a Varian Cary Eclipse UV spectrophotometer at intervals of 30 seconds for 6.5 minutes until no further increase in absorbance of $\mathbf{4 b}(560 \mathrm{~nm})$ was observed.

\subsection{FRET efficiency}

Micelles were prepared as described in section 2.4 with $78 \mu \mathrm{L}$ of $3\left(0.08 \mathrm{mg} \mathrm{mL}^{-1}\right)$ and varying volumes of $4\left(0.2 \mathrm{mg} \mathrm{mL}^{-1}\right)$ to obtain molar ratios $1: 0.5-10$ of $3: 4$ and hydrated with $3 \mathrm{~mL}$ PBS to form micelles. The FRET efficiency was determined by allowing the photo-transformation of $\mathbf{4 a}$ to $\mathbf{4 b}$ while the concentration of $\mathbf{3}$ remained constant. Fluorescence emission spectra of 3 were recorded (Ex 525nm Em $545 \mathrm{~nm}$ ) before and after UV light exposure using a Varian Cary Eclipse Fluorescence spectrophotometer.

\subsection{In vitro triggered release}

Micelles were prepared as above using $0.176 \mathrm{~mL}$ of $3\left(0.2 \mathrm{mg} \mathrm{mL}^{-1}\right)$ with $0.6 \mathrm{~mL}$ of 4 (0.5 $\left.\mathrm{mg} \mathrm{mL}^{-1}\right)$ and $2 \mathrm{~mL}$ polymer $\left(2.5 \mathrm{mg} \mathrm{mL}^{-1}\right)$ and hydrated with $2 \mathrm{~mL}$ PBS. Release studies were undertaken using Franz diffusion cells and dialysis membrane (MWCO 14,000). $200 \mu \mathrm{L}$ of the micelle formulation was loaded into donor compartment while the acceptor chamber comprised of PBS and maintained at $37^{\circ} \mathrm{C}$. The contents of the donor chamber were irradiated with UV light for fixed time periods of 2, 4, 6, 8, 10 and 12 mins and solutions were analysed using fluorescence spectroscopy at Ex360nm-EM 637nm. Similarly, control studies were conducted in the absence of UV light. For determining stability and reproducibility of the system, micelles containing $\mathbf{3}$ and $\mathbf{8}$ were loaded onto 
Franz diffusion cells and subjected to cycles of 5 minutes UV light and 20 minutes dark conditions during which samples were scanned for fluorescence emission of 3 at Ex $525 \mathrm{~nm}$-Em 540nm at 5 minutes intervals for 20 minutes.

\subsection{Observation of FRET in HeLa cells}

HeLa cells were incubated in modified DMEM with 10\% FBS and 1\% Pen/strep in 96 well plates at a cell density of $5 \times 10^{3}$ cells in each well and allowed to adhere overnight. When $60 \%$ confluency was reached, $2 \mathrm{~mL}$ micelle solutions were prepared containing either $3\left(0.176 \mathrm{~mL}\right.$ of $\left.0.2 \mathrm{mg} \mathrm{mL}^{-1}\right)$ and $4\left(0.6 \mathrm{~mL}\right.$ of $\left.0.5 \mathrm{mg} \mathrm{mL}^{-1}\right)$ or just $3(0.6 \mathrm{~mL}$ of $\left.0.5 \mathrm{mg} \mathrm{mL}^{-1}\right) .50 \mu \mathrm{l}$ of this solution were added to the wells and incubated for $18 \mathrm{~h}$. The cells were then washed twice with PBS and the fluorescence emission determined using an ELISA plate reader (Ex 485nm and Em 520nm). For confocal microscopy, cells were treated as mentioned above and imaged using a Leica DMI6000b inverted microscope with a 40x oil immersion lens. All images were analysed using LAS AF v2.3.6 software.

\subsection{Comparative release study to quantify triggered release by FRET}

Release studies were conducted on Franz diffusion cells using dialysis membrane. Briefly micelles loaded with $\mathbf{3}$ and $\mathbf{8}$ were loaded into acceptor compartment and the donor compartment was filled with PBS maintained at $37^{\circ} \mathrm{C}$. Micelles were irradiated with UV light for 5 minutes after which they were subjected to light and dark conditions for 20 minutes. Samples were taken at 5 minute interval and observed for UV absorbance at $345 \mathrm{~nm}$ for $\mathbf{8 a}$ and fluorescence emission of $\mathbf{3}$ following a 20 minute equilibration period in visible light conditions. Similar studies were conducted without UV trigger.

\section{Results and Discussion}

\subsection{Synthesis of compounds}

The synthesis of compound 1 was achieved by the synthetic procedure outlined in Scheme S1 (Supporting information). Successful product formation was confirmed by 
mass spectroscopy and ${ }^{1} \mathrm{H}$ NMR spectroscopy. Compound 3 was synthesized to increase the hydrophobicity of the FRET donor and hence ensure continued encapsulation within the micelle. Synthesis was achieved by a modification of a previous procedure [18] with characterisation detailed in section 2.3.1. Compound 4 was synthesized as described in scheme 2 and again successful product formation was confirmed by ${ }^{1} \mathrm{H}$ NMR and mass spectroscopy. Compound $\mathbf{8}$ is a novel compound and was formed by an esterification between 6 and 7 in a 1:1 stoichiometry with a yield of $94 \%$. Successful product formation was again confirmed by ${ }^{1} \mathrm{H}$ NMR and mass spectroscopy, as detailed in section 2.3.2.

\subsection{Preparation and characterisation of micelles}

DLS measurements of micelles loaded with 3 and 4 indicate an average particle size of $27.5 \pm 0.98 \mathrm{~nm}$ with PDI $0.416 \pm 0.009$ and surface charge of $-1.67 \pm 0.73$ as determined by zeta potential measurements. These observations were in agreement with those observed previously by Yildiz et al using the same polymeric micelle with encapsulated cargo [18]. However when 4 was replaced by 8 , the micelle size increased to $45.93 \pm 2.72 \mathrm{~nm}$ and PDI was $0.346 \pm 0.04$ with $-2.05 \pm 0.61$ zeta potential. This slight increase in micelle size may be attributed to the greater rigidity of 8 causing a larger hydrophobic internal core within the micelle. There was no major change in the PDI and zeta potential values for micelles following encapsulation with regards to content indicating successful incorporation of $\mathbf{8}$ inside the micelle. Figure $3 \mathrm{a}$ shows a representative particle size distribution graph for micelles loaded with $\mathbf{3}$ and $\mathbf{4}$, while a scanning electron microscopic image of micelles loaded with $\mathbf{3}$ and $\mathbf{8}$ (Figure 3b) show well-formed particles with spherical morphology. 

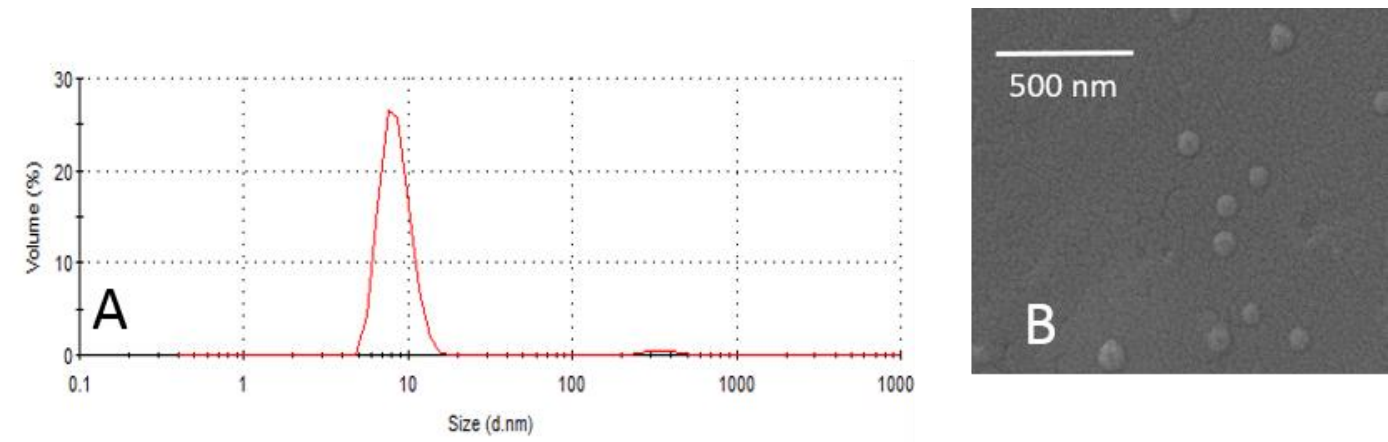

Figure 3. A. Dynamic light scattering displaying the hydrodynamic radius of micelles. B. SEM image of micelles

\subsection{Quantification of photo physical transformation of $4 a$ to $4 b$}

For efficient FRET to occur between a donor-acceptor pair two main criteria must be met. First, the donor and acceptor molecules must be in close proximity to each other and secondly, the emission spectrum of the donor must overlap effectively with the absorption spectrum of the acceptor. In the context of the micellar delivery system described above, as both the donor and acceptor are originally confined within the micelle, a nanoscale distance between the two molecules can be guaranteed. [34]. In terms of spectral overlap, the absorbance spectrum of $\mathbf{4 a}$ encapsulated within the micelle was determined to have a maximum absorbance centered at $360 \mathrm{~nm}$. Upon activation by UV light, $4 a$ undergoes a ring opening of the spiro carbon to its corresponding merocyanine, $\mathbf{4 b}$ (Figure 1). The merocyanine is zwitterionic, and therefore more hydrophilic. It has also an elongated area of conjugation and therefore induces a significant bathochromic shift to a new absorbance maximum at 550nm which coincides with the emission wavelength of 3 (Figure 4) when excited at $525 \mathrm{~nm}$. 


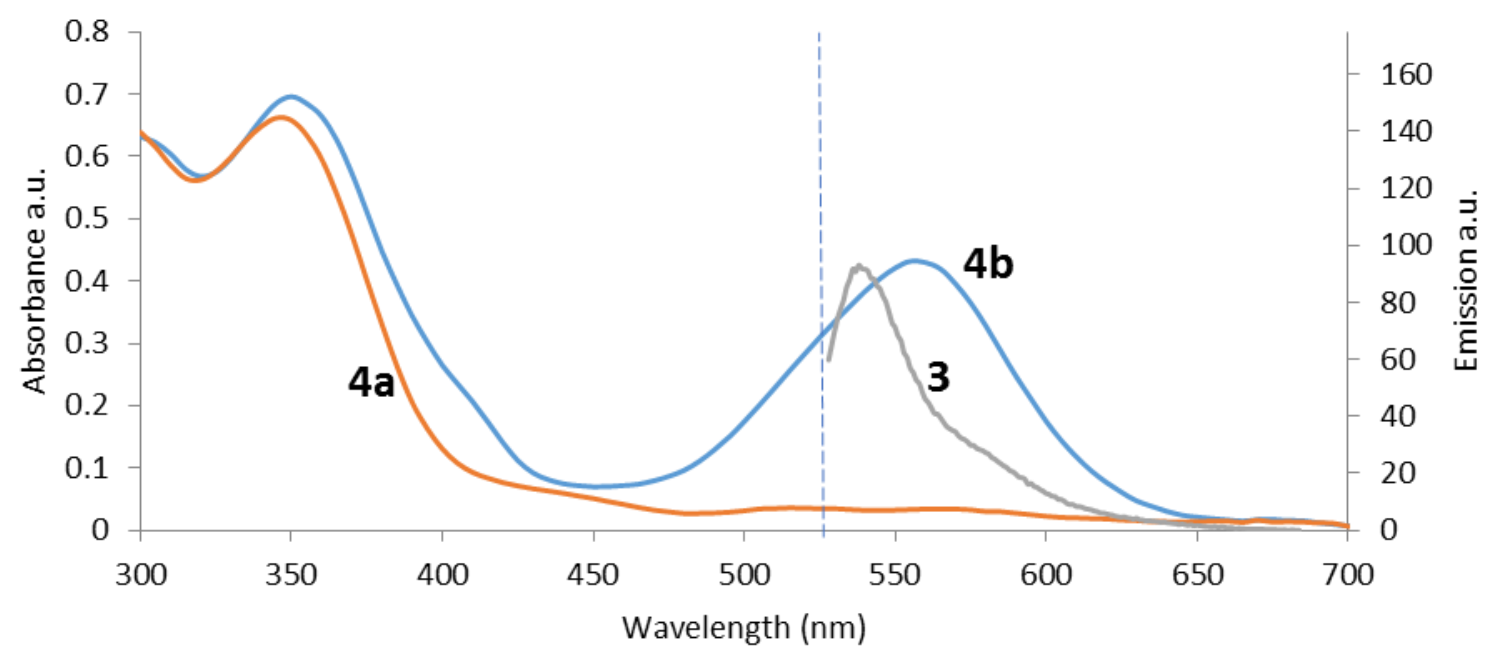

Figure 4. Absorbance spectra of $\mathbf{4 a}$ and following photoconversion to $\mathbf{4 b}$ with the emission spectra of 3 with Ex $525 \mathrm{~nm}$.

This spectral cohesion of absorbance and emission of $\mathbf{4 b}$ and $\mathbf{3}$ is imperative for energy transfer from 3 (the fluorescent donor) and $\mathbf{4 b}$ (the photochromic acceptor. Nevertheless, the time required for conversion of $\mathbf{4 a}$ to $\mathbf{4 b}$ can significantly affect the energy transfer from $\mathbf{3}$ to $\mathbf{4 b}$. Hence we irradiated $\mathbf{4 a}$ with UV light and monitored the UV-Vis spectrum at increments of 30 seconds in aqueous medium and found that it required 5 minutes irradiation for complete conversion from $\mathbf{4 a}$ to $\mathbf{4 b}$ as shown in Figure 5.

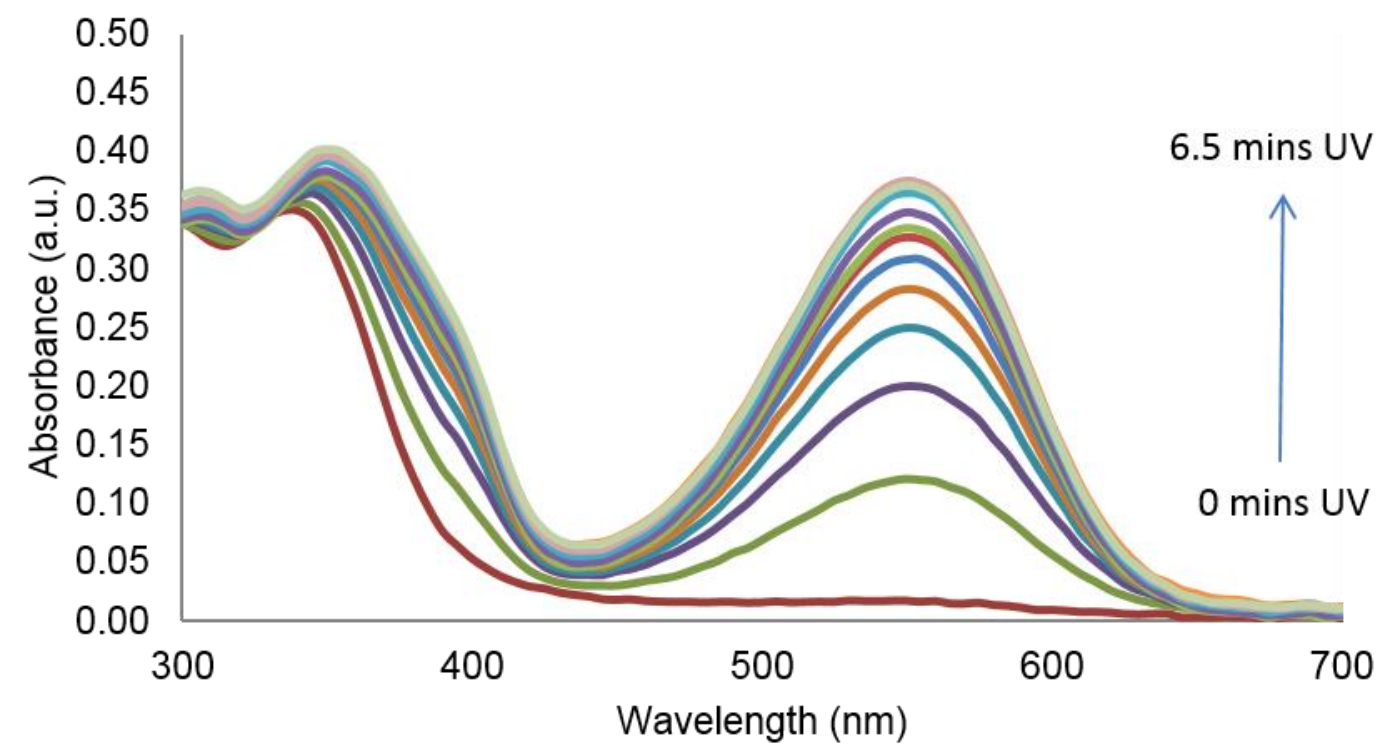


Figure 5. Absorbance spectra of $\mathbf{4 b}$ at $\lambda \max 550 \mathrm{~nm}$ increasing with increasing exposure to UV light of $365 \mathrm{~nm}$. Spectra displayed following exposure to 0, 0.5, 1.0, 1.5,2, 2.5, 3, 3.5, 4, 4.5, 5, 5.5, 6 and 6.5 mins UV light at $465 \mathrm{~nm}$ from a fixed distance.

After 5 minutes, the absorption reached a plateau beyond which there was no increase in the absorption intensity. However complete conversion of $\mathbf{4 a}$ to $\mathbf{4 b}$ took 12 minutes in DMF medium which can be explained by the polar nature of $\mathbf{4 b}$ enabling faster conversion in aqueous medium (S4). The polar nature of $\mathbf{4 b}$ is fundamental to encourage its release from within the micelle to the surrounding polar aqueous environment, enabling a triggered release of micellar content.

\subsection{FRET efficiency between 3 and $4 b$}

In order to identify the ratio of $\mathbf{3}$ to $\mathbf{4 b}$ which allows maximum energy transfer between the fluorophore and photochrome, the two compounds were encapsulated into the micelles at different molar ratios and the observed decrease in fluorescence emission of $\mathbf{3}$ following irradiation withUV light for 5 minutes to facilitate the conversion of $\mathbf{4 a}$ to $\mathbf{4 b}$. Figure 6 shows the emission profile of $\mathbf{3}$ at varying ratios of $\mathbf{4 b}$. As expected, the emission of $\mathbf{3}$ was highest when there was no $\mathbf{4 b}$ present in the micelle (spectrum a). As the concentration of $\mathbf{4 a}$ in the micelles increased, more $\mathbf{4 a}$ was converted to $\mathbf{4 b}$ upon irradiation with UV light and quenched the emission of 3 at 540nm proportionately (spectra b-h).In addition, emission from $\mathbf{4 b}$ at $637 \mathrm{~nm}$ was observed to increase upon increasing $\mathbf{4 a}$ concentration indicating a successful energy transfer between $\mathbf{3}$ and $\mathbf{4 b}$. However, the plot of percentage depletion in fluorescence emission of 3 (Figure 6 insert) shows that a plateau was reached after a ratio $1: 6$ of $3: 4 \mathbf{b}$ suggesting a saturation concentration was reached with no more 3 available for energy transfer. This suggests that the optimal FRET molar ratio between donor and acceptor to allow for quantitative analysis is $1: 6$. This is reflective of the difference in extinction coefficient between our donor and acceptor moieties. This was the ratio chosen for all subsequent studies. 


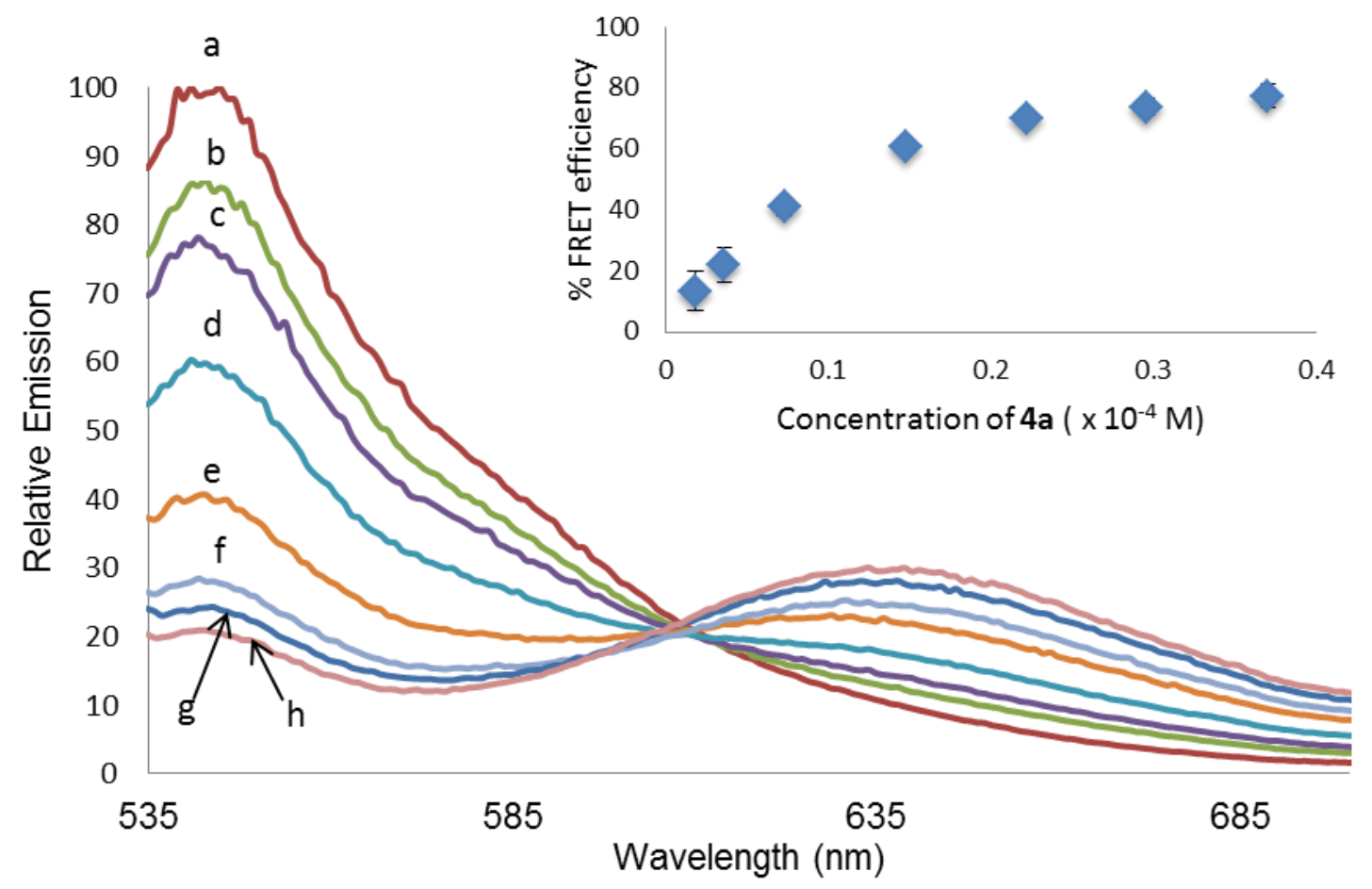

Figure 6. Fluorescence emision of $\mathbf{3}$ following exposure to varying molar ratios of $\mathbf{4 a}$ and photoconversion to $\mathbf{4 b}$. a: no UV exposure and b-h: solutions were exposed to 5 mins UV light at $365 \mathrm{~nm}$ from a fixed distance and molar ratios of compunds bodipy $3:$ merocyanine $4 \mathrm{~b} \quad 1: 0.5$; 1:1, 1:2, 1:4, 1:6, 1:8 and 1:10 consecutively. Insert: FRET efficiency of $\mathbf{3}$ and $\mathbf{4}$ following exposure to 5 mins UV light at $365 \mathrm{~nm}$ from a fixed distance. Concentration of 3 remains constant at $3.64 \mu \mathrm{M}$. Percentage efficiency was determined by the relation depletion in the emission of 1 at $545 \mathrm{~nm}, \mathrm{n}=3$.

\subsection{In vitro triggered release}

UV light acts as a trigger for photoinduced transformation of $\mathbf{4 a}$ which is hydrophobic with a closed ring system to an open ring $\mathbf{4 b}$ which is polar in nature with higher solubility in aqueous medium. The hydrodynamic properties of micelles allows $4 b$ to easily come out of the system permitting release of encapsulated cargo. Continuous photoactivation of $\mathbf{4 a}$ within the micelle lead up to $24 \%$ release of $\mathbf{4 b}$ into the surrounding environment within 12 minutes which was significantly higher than the $5 \%$ release in the absence of photoactivation as seen in Figure 7. This design of a triggered fast release system is essential for successful release of drugs attached to $\mathbf{4}$ for therapeutic applications. 


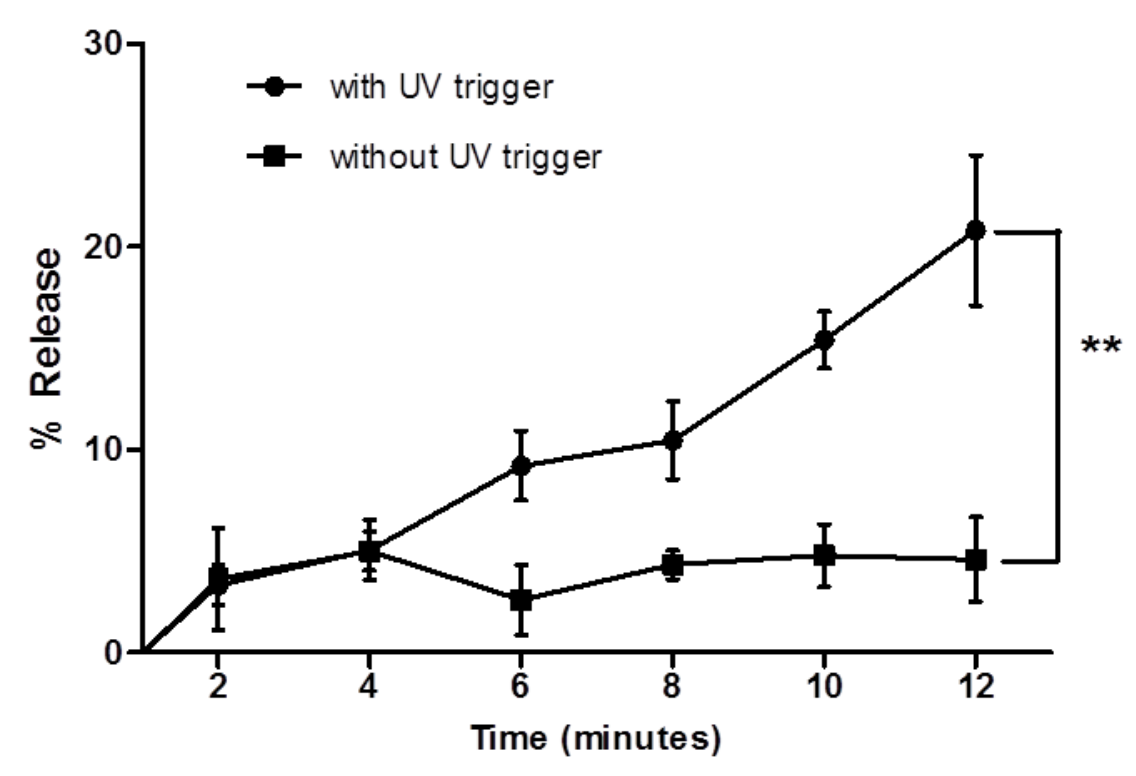

Figure 7. In-vitro triggered release of $\mathbf{4 b}$ from micelles after continuous activation with UV light for 12 minutes and no UV activation. ${ }^{* *}$ indicates $p<0.005$.

\subsection{Reproducibility of system}

The integration of photoswitchable assemblies with fluorophores capable of resonance energy transfer allows the formation of a system which has the ability to switch on and off on demand. Figure 8 shows the fluorescence emission of $\mathbf{3}$ in the presence of $\mathbf{8}$ and subsequent photochromic switching between the spiropyran form (8a) to its merocyanine counterpart (8b) indicating the reproducibility of the system. 


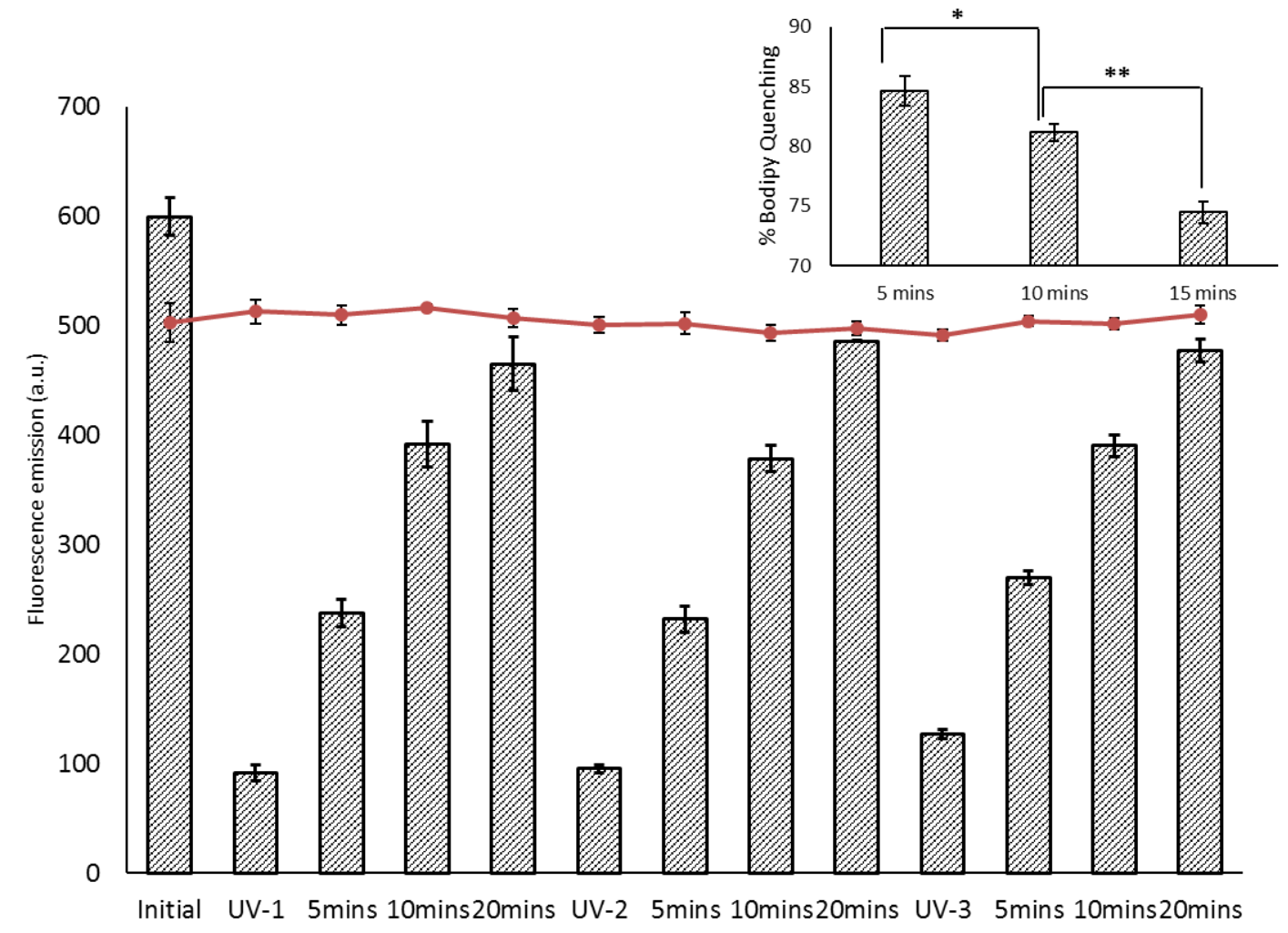

Figure 8. Bar chart: Fluorescence emission of $\mathbf{3}$ within micelles loaded with $\mathbf{8 a}$ following cycles of UV exposure ( $365 \mathrm{~nm}, 5 \mathrm{mins}$ ) leading to conversion of $\mathbf{8} \mathbf{a}$ to $\mathbf{8 b}$ and subsequent resting time in dark conditions permitting reversion of $\mathbf{8 b}$ back to $\mathbf{8 a}$. Line graph: control with micelles containing only $\mathbf{3}$.Insert: \% quenching of $\mathbf{3}$ following UV irradiation. ${ }^{* *}$ indicates $p<0.005$

Compound $\mathbf{8}$ was created as a prodrug, to contain an API (Ibuprofen) covalently linked to the photochromic spiropyran moiety. Once released from the internal core of the micelle it is anticipated that it would be subjected to hydrolysis via esterase's enzymes and hence release the API. When there was no $\mathbf{8 b}$ present in the system (in the absence of UV light), there was a significantly high emission of 3. This emission was quenched upon photoactivation of $\mathbf{8} \mathbf{a}$ to $\mathbf{8} \mathbf{b}$ as the absorption signature of $\mathbf{8} \mathbf{b}$ overlaps with emission signature of $\mathbf{3}$. As $\mathbf{8} \mathbf{b}$ slowly reverted back to $\mathbf{8 a}$ owing to its reversibility in heat and visible light conditions, the emission of $\mathbf{3}$ slowly increased. The hydrophilic nature of $\mathbf{8 b}$ encourages it to transcend the hydrophobic internal core of the micellar system into the wider aqueous environment. Although the system was kept in the dark, there were three cycles of 5 minute irradiation, allowing for significant movement outside the micelle. This movement was observed as a decrease in the quenching 
efficiency of $\mathbf{3}$ upon subsequent photoactivation cycles (Figure 8 insert) as less $\mathbf{8 b}$ was present within nanoscale distance for FRET to successfully take place between the two molecules in each subsequent excitation. This decrease in the quenching of emission of $\mathbf{3}$ is of similar magnitude to the \% release of internalised compound $\mathbf{4}$, observed in Figure 7, with $19 \%$ release after 10 minutes of 8 when compared to the $15 \%$ release of 4 after 10 minutes displayed in Figure 7 . The increase in release is attributed to the time lapse between UV stimulation and subsequent photoconversion allowing for more hydrophobic $\mathbf{8 b}$ to leave the micelle. It is seen from Figure 8 that a further fluorescence quenching of $74.4 \%$ is recorded after 15 mins UV irradiation and would suggest that $25.6 \%$ of $\mathbf{8}$ has been released. A similar effect was seen in light conditions, but the \% of quenching of $\mathbf{3}$ was slightly less, due to the faster photoconversion back to the original more hydrophobic spiropyran moiety (8a), ensuring that less compound was released and hence more available for the subsequent energy transfer to the donor (S6). Micelles loaded with only 3 did not show any changes in fluorescence emission after photoactivation and after subsequent resting periods, in addition there was limited photobleaching of $\mathbf{3}$ after UV irradiation.

\subsection{Observation of FRET in HeLa cells}

Encapsulation of cargo within micelles enables them to be transported across the cell membrane leading to better cellular uptake owing to their biocompatibility and size. In order to determine the feasibility of communication and triggered release from within the micelles, we incubated HeLa cells with micelles loaded with $\mathbf{3}$ and $\mathbf{4 a}$ and enabled the photoconversion of $\mathbf{4 a}$ to $\mathbf{4 b}$ present within the cells to confirm FRET communication between $\mathbf{3}$ and $\mathbf{4 b}$. As seen in Figure 9, fluorescence emission of $\mathbf{3}$ fluctuated drastically according to status of $\mathbf{4 b}$ present within the cells, as a direct result of molecular communication between them. The ability of $4 b$ to switch back to $4 a$ in the presence of visible light broke the communication between $\mathbf{3}$ and $\mathbf{4 b}$ allowing the emission of $\mathbf{3}$ to be observed. These results in HeLa cells support our previous observations in vitro conditions in section 3.6. It can be seen that immediately following 5 minutes UV irradiation there is a $82.5 \%$ quench in the fluorescence emission of 3 , attributed to the energy transfer to the acceptor moiety, $\mathbf{4 b}$. Upon subsequent photoactivation cycles of 
$\mathbf{4 b}$ there was significantly less quenching of the emission from our donor compound $\mathbf{3}$ ( $75.3 \%$ and $64.2 \%$ respectively). This can be attributed to the more polar $\mathbf{4 b}$ form leaving the micelle DDS $(24.7 \%$ and $35.8 \%$ released after 10 and 15 minutes irradiation).

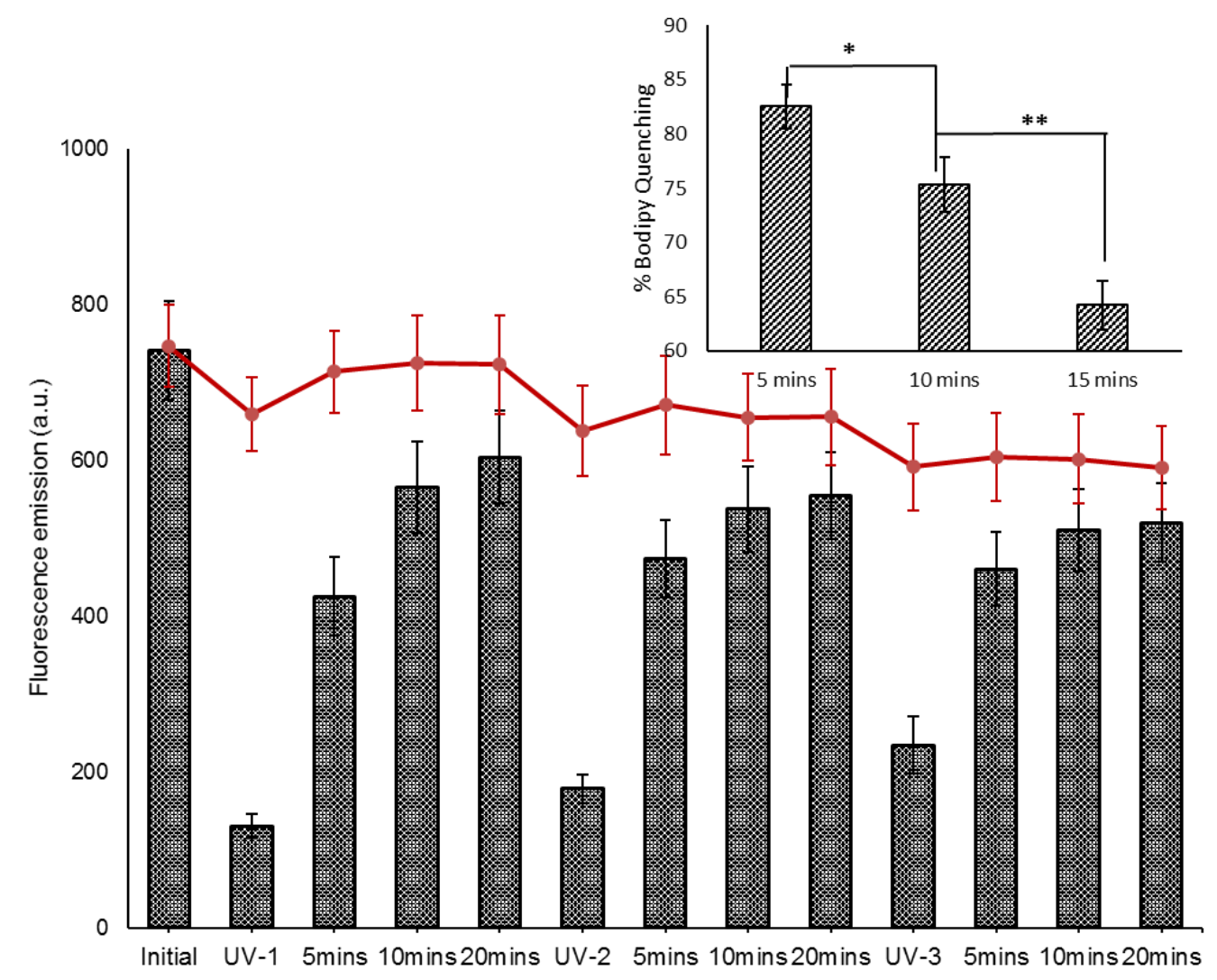

Figure 9. Bar chart: Fluorescence emission of $\mathbf{3}$ in HeLa cells incubated overnight with micelles loaded with 3 and $4 a$ and following cycles of UV exposure ( $365 \mathrm{~nm}, 5$ mins) leading to conversion of $\mathbf{4 a}$ to $\mathbf{4 b}$ and subsequent resting time in visible light conditions permitting reversion of $\mathbf{4 b}$ back to $\mathbf{4 a}$. Line graph: control using micelles containing $\mathbf{3}$ only. Insert: $\%$ quenching of $\mathbf{3}$ following UV irradiation. ${ }^{* *}$ indicates $p<0.005,{ }^{*}$ indicates $p<0.05$.

As expected the emission of $\mathbf{3}$ lapsed back faster in visible light conditions compared with dark conditions (S7), further confirming that the photoconversion of $\mathbf{4 b}$ to $\mathbf{4 a}$ is faster in the presence of visible light and is indirectly communicated in the form of higher emission of $\mathbf{3}$. Additionally, the quenching effect after subsequent UV irradiation cycles in the dark was similar to that seen in light conditions. Similarly, observations of 
cells by confocal microscopy indicated significant reduction in fluorescence emission of $\mathbf{3}$ on photoactivation of $\mathbf{4 b}$ confirming its presence within cells (Figure 10).
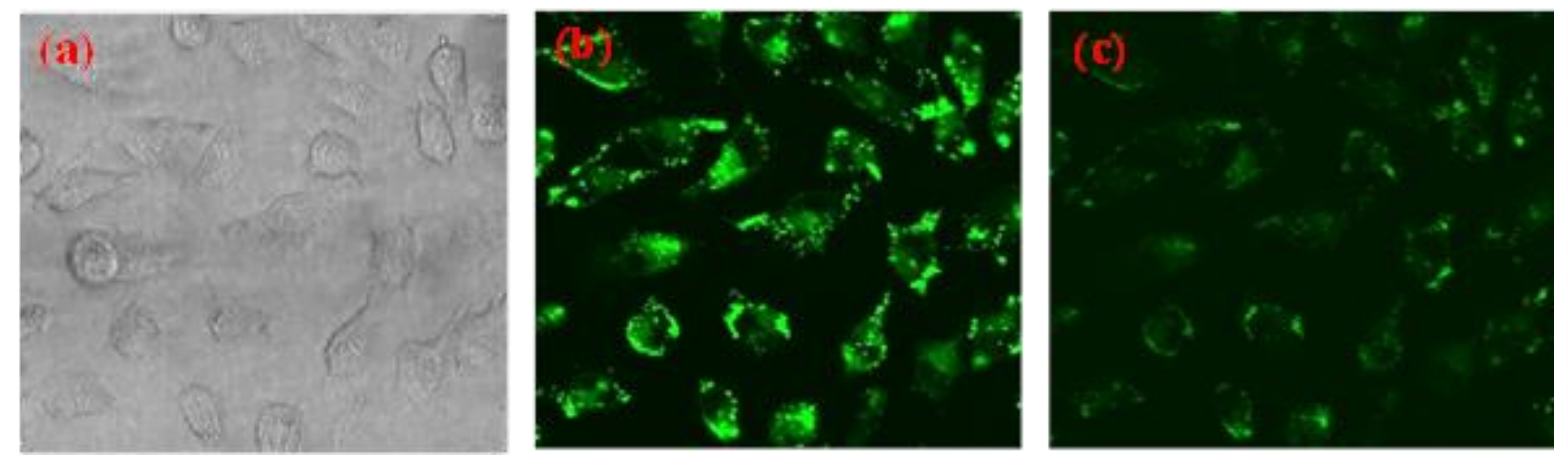

Figure 10. Confocal microscopic images of HeLa cells incubated with micelles loaded with 3 and 4a showing (a) Clear field (b) Fluorescence emission of 3 (Ex 514nm, Em 520-590nm) before UV exposure (c) Fluorescence emission of $\mathbf{3}$ after UV exposure (365nm, 5 mins).

\subsection{Real time quantification of encapsulated cargo}

The photoswitchable nature of $\mathbf{8}$ and its molecular communication with $\mathbf{3}$ can prove beneficial in real time quantification of release of encapsulated materials from within the micellar environment. To quantify this occurrence, micelles loaded with $\mathbf{3}$ and $\mathbf{8}$ were loaded on to dialysis membranes in Franz diffusion cells and photoactivated for 5 minutes to allow conversion of $\mathbf{8 a}$ to $\mathbf{8 b}$ resulting in its release from the micellar environment recorded over 20 minutes of resting time in both dark and visible light conditions. Two parameters were measured simultaneously at various time points in an attempt to correlate the communication seen through $\mathbf{3}$ with release of $\mathbf{8}$. This was achieved by monitoring the amount of $8 \mathbf{a}$ present within the micelles by absorbance at $345 \mathrm{~nm}$. Following removal of the sample for analysis a set period of 20 minutes was observed with the sample subjected to visible irradiation, to ensure that all 8 was in the spiropyran form, $\mathbf{8} \mathbf{a}$. The results of the depletion in $\mathbf{8 a}$ absorbance can be seen in Figure 11a. The simultaneous measurement of bodipy emission (3) was collected, following the original 5 mins UV irradiation, each sample removed for analysis was subjected to 20 minutes visible light before the emission of $\mathbf{3}$ was recorded, the decrease in quenching is plotted in Figure 11b. From Figure 11 a good correlation is seen between both the fluorescence increase from 3 and the absorbance of $\mathbf{8 a}$. The 
largest magnitude of change is observed from the UV stimulation in dark conditions, this is expected as $\mathbf{8 b}$ would favour the more polar environment. Specifically, a $8.4 \%$ decrease in $\mathbf{8 a}$ absorbance is observed after 10 minutes, indicting a transfer of $\mathbf{8}$ across the dialysis membrane. This is indirectly communicated through a $7.0 \%$ increase in the fluorescence emission of 3 (figure 11b). Similarly a $17.4 \%$ decrease in absorbance of $\mathbf{8 a}$ is seen at 20 minutes compared to $11.6 \%$ increase in fluorescence emission of $\mathbf{3}$ at the same time point. Visible light conditions led to conversion of $\mathbf{8 b}$ back to $\mathbf{8 a}$ leading to lesser release of only about $7 \%$ from micelles which was reflected as approximately $4 \%$ increase in fluorescence emission of 3 . However there was negligible release in the absence of a UV trigger and is suitably revealed as insignificant increase in fluorescence emission of $\mathbf{3}$. This close correlation between the FRET communication when compared to the direct measurement of remaining spiropyran would suggest that there is indeed potential to further develop these smarter DDSs.
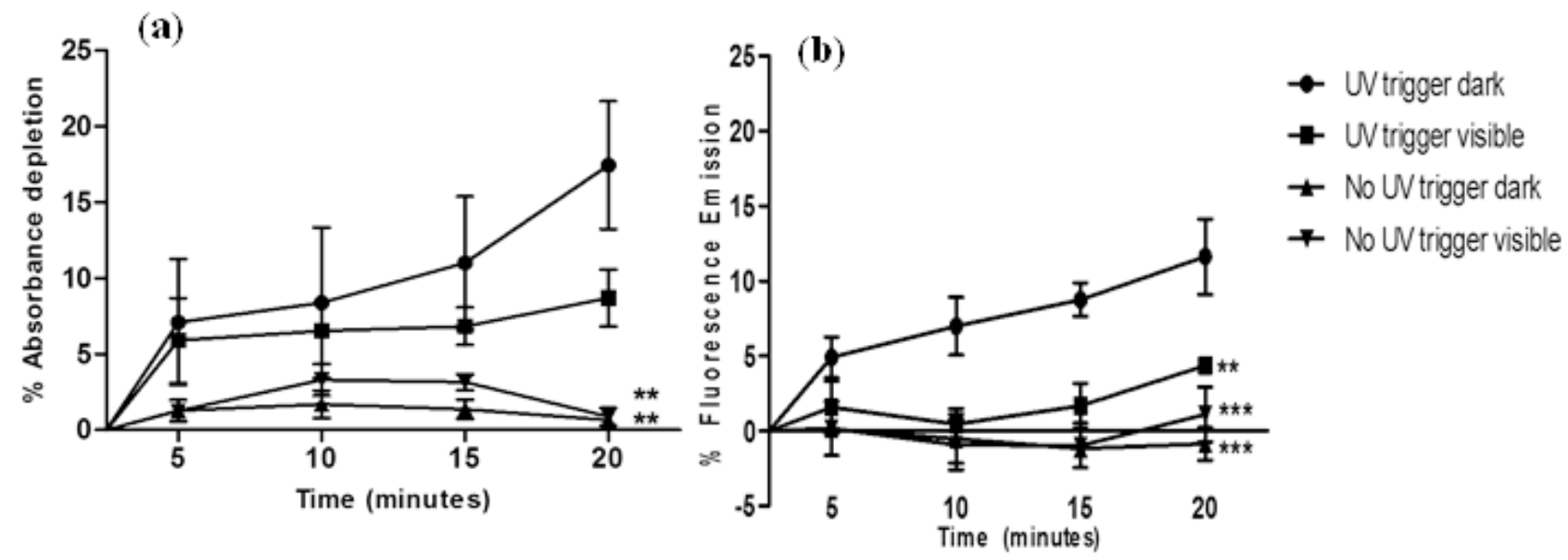

Figure 11. (a) In vitro release of $\mathbf{8 a}$ from micelles with and without UV trigger and subsequent resting time in dark and visible light conditions measured by decrease in UV absorbance at 345 nm. (b) Observation of \% increase in fluorescence emission of 3 at Ex $503 \mathrm{Em} 514 \mathrm{~nm}$ measured concomitantly with release of $8 \mathbf{a} .{ }^{* *}$ indicates $p<0.005,{ }^{* * *}$ indicates $p<0.0005$.

\section{Conclusion}

The number of smart DDSs capable of real time communication with concomitant stimulated drug release is increasing in response to the nanotechnology revolution [35]. The need for variation between the mechanism of stimulus, as well as the parameter 
involved in communication is paramount to the success of these advanced materials so to allow these nano-platforms to reach the full echelon of their potential. Recent examples illustrating this diversity can be seen by Huang at el. [36] whereby they have incorporated the anticancer agent doxorubicin into a supramolecular nanoparticle and also double up its use as the FRET acceptor to allow self-communicating. Another interesting example is seen by Du et al. [37] and their incorporation of five stimuli responsive moieties on to their NP.

We have designed a photo-activated DDS capable of real time communication using the photochromic properties of spiropyrans and exploiting the differences in physiochemical properties. By adopting a prodrug approach, we have developed an ibuprofenspiropyran analogue, which has displayed significant stimulated release from within a micelle environment. In addition, with the incorporation of a hydrophobic bodipy compound within the micelle hydrophobic core, we have created a FRET communication between the two species present within the micelle that has shown significant potential for real time analysis of content. In vitro analysis has confirmed this system remains intact within Hela cells. This smart DDS has the potential to be adapted for a number of different API, by simply linking the API with the spiropyran through an ester or potentially an amide bond, thus increasing application for such nanoplatforms to include a large number of drugs with the only prerequisite being that they contain a suitable reactive functional groups.

\section{Acknowledgements}

This work was funded by the University of Ulster.

\section{References}

[1] M. Hruby, S. Filippov K, P. Stepanek, Smart polymers in drug delivery systems on crossroads: Which way deserves following? European Polymer Journal. 65 (2015) 82-97.

[2] A. Brun-Graeppi, C. Richard, M. Bessodes, D. Scherman, O. Merten, Cell Microcarriers and Microcapsules of Stimuli-Responsive Polymers, J. Controlled Release. 149 (2011) 209-224. 
[3] C. Ashley, E. Carnes, G. Philips, D. Padilla, P. Durfee, P. Brown, T. Hanna, J. Lui, B. Phillips, M. Carter, N. Carroll, X. Jiang, D. Dunphy, C. Willman, D. Petsev, D. Evans, A. Parikh, B. Chacherian, W. Wharton, D. Peabody, C. Brinker, The targeted delivery of multicomponent cargos to cancer cells by nanoporous particle-supported lipid bilayers. Nature Materials. 10 (2011) 389-394.

[4] M. Zayats, M. Kanwar, M. Ostermeier, P. Searson, Tuning protein recognition at the molecular level, Macromolecules. 44 (2011) 3966-3972.

[5] T. Ramasamy, H. B. Ruttala, B. G. Kanu, B. K. Poudel, H.-G. Choi, C. S. Yong and J. O. Kim, Smart chemsirty based nanosized drug delivery systems for systemic applications: A comprehensive review, J. Controlled Release. 258 (2017) 226-253.

[6] D. Furgeson, M. Dreher, A. Chilkoti, Structural optimisation of a 'smart' doxorubicin-polypeptide conjugate for thermally targeted delivery of solid tumors, J. Controlled Release. 110 (2006) 362-369.

[7] M. Hruby, C. Konak, K. Ulbrich, Polymeric micellar pH-sensitive drug delivery system for doxorubicin, J. Controlled Release. 103 (2005) 137-148.

[8] S. Banerjee, D. Chen, A multifunctional magnetic nanocarrier bearing fluorescent dye for targeted drug delivery by enhanced two photon triggered release, Nanotechnology. 20 (2009) 185103-185112.

[9] S. Murdan, Electro responsive drug delivery from hydrogels, J. Controlled Release. 92 (2003) 1-17.

[10] N. Nomikou, C. Arthur, C. Sterrett, B. McCaughan, J.F. Callan, A.P. McHale, Ultrasound enhanced photoactivation of indocyanine green in-vitro and in-vivo implications for targeted cancer therapy, Chem.Med.Chem. 7 (2012) 1465-1471.

[11] L. Glangchi, M. Caldorera-Moore, L. Shi, K. Roy, Nanoimprint lithography based fabrication of shape specific enzymatically-triggered smart nanoparticles, J. Controlled Release. 125 (2008) 263-272.

[12] C. McCoy, C. Rooney, C. Edwards, D. Jones, S. Gorman, Light-triggered molecule-scale drug dosing devices, J. Am. Chem. Soc. 129 (2007) 9572-9573. 
[13] J. Honey, J. Rijo, A. Anju, K. Anoop, Smart polymers for the controlled delivery of drugs - a concise overview, Acta Pharmaceutica Sinica B. 4 (2014) 120-127.

[14] S. Swaminathan, Photoresponsive polymer nanocarriers with multifunctional cargo, Chem. Soc. Rev. 43 (2014) 4167-4178.

[15] B. Lukyanov, M. Lukyanova, Syropyrans: Synthesis, properties and application. Chem.Heterocycl.Compd. 41 (2005) 281-311.

[16] Q. Zhou, Y. Zhu, P. Sheng, Z. Wu, Q. Cai, A highly selective and reversible fluorescent $\mathrm{Cu} 2+$ and $\mathrm{S} 2$ - probe under physiological conditions in live cells, RSC Advances. 4 (2014) 46951-46954.

[17] M. Balter, M. Hammarson, P. Remon, S. Li, N. Gale, T. Brown, J. Andreasson, Reversible energy transfer switching on a DNA scaffold, J. Am. Chem. Soc. 137 (2015) 2444-2447.

[18] I. Yildiz, S. Impellizzeri, E. Denniz, B. McCaughan, J. Callan F, F. Raymo, Supramolecular Strategies to Construct Biocompatible and Photoswitchable Fluorescent Assemblies, J. Am. Chem. Soc. 133 (2011) 871-879.

[19] F. Khan, R. Katara, S. Remteke, Enhancement of bioavailability of cefpodoxime proxetil using different polymeric microparticles, APPS Pharm.Sci.Tech. 11 (2010) 1368-1372.

[20] M. Talelli, M. Barz, C. Rijcken, F. Kiessling, W. Hennink, T. Lammers, Corecrosslinked polymeric micelles: Principles, preparation, biomedical applications and clinical translation, Nano Today. 10 (2015) 93-117.

[21] G. Kohli, H. Kierstead, J. Venditto, L. Walsh, C. Szoka, Designer lipids for drug delivery: From heads to tails, J. Control. Release. 190 (2014) 274-287.

[22] H. Kapahi, Implication of nanofibers in oral drug delivery, Curr. Pharm. Des. 21 (2015) 2021-2036.

[23] Y. Yang, J. Bugno, S. Hong, Nanoscale polymeric penetration enhancers in topical drug delivery, Polymer Chemistry. 9 (2013) 2651-2657. 
[24] S. Hocine, Thermoresponsive self-assembled polymer colloids in water, Soft Matter. 9 (2013) 5839-5861.

[25] A. Di Crescenzo, V. Ettorre, A. Fontana, Non-covalent and reversible functionalization of carbon nanotubes, Beilstein J.Nanotechnol. 5 (2014) 1675-1690.

[26] R. Singh, W. James, J. Lillard, Nanoparticle based targeted drug delivery, Exp. Mol. Pathol. 86 (2009) 215-223.

[27] K. Miyata, R. Christie, K. Kataoka, Polymeric micelles for nano-scale drug delivery, React Funct Polym. 71 (2011) 227 - 234.

[28] Q. Xing, N. Li, D. Chen, W. Sha, Y. Jiao, X. Qi, Q. Xu, J. Lu, Light-responsive amphiphilic copolymer coated nanoparticles as nanocarriers and real-time monitors for controlled drug release, Journal of Materials Chemistry B. 2 (2014) 1182-1189.

[29] X. Li, N. Hao, H. Chen, J. Xu, Tumor-Marker-Mediated 'on-demand' drug release and real time monitoring system based on multifunctional mesoporous silica nanoparticles, Anal. Chem. 86 (2014) 10239-10245.

[30] J. Lai, B. Shah, E. Garfunkel, K. Lee, Versatile Fluorescence Resonance Energy Transfer Based Mesoporous Silica Nanoparticles for Real-Time Monitoring of Drug Release, ACS Nano. 7 (2013) 2741-2750.

[31] F.M. Raymo, S. Giordani, Signal Processing at the Molecular Level, J. Am. Chem. Soc. 123 (2001) 4651-4652.

[32] L. Baumann, K. Scholler, D. de Courten, D. Marti, M. Frenz, M. Wolf, R. Rossi M, L. Scherer J, Development of light-responsive porous polycarbonate membranes for controlled caffeine delivery, RSC Adv. 3 (2013) 23317-23326.

[33] C. Martin, E. Dolmazon, K. Moylan, C. Fowley, A. McHale, J. Callan, B. Callan, A charge neutral, size tuneable polymersome capable of high biological encapsulation efficiency and cell permeation, Int. J. Pharm. 481 (2015) 1-8.

[34] M. Linlin, Y. Fan, Z. Jie, Application of fluorescence resonance energy transfer in protein studies, J. Mol. Struct. 1077 (2014) 87-100. 
[35] M. Karimi, P. S. Zangabad, S. Baghaee-Ravari, M. Ghazadeh, H. Mirshekari, M. R. Hamblin, Smart Nanostructures for cargo delivery: Uncaging and Activating by Light, J. Am. Chem. Soc., 139 (2017) 4584-4610.

[36] G. Yu, R. Zhao, D. Wu, F. Zhang, L. Shao, J. Zhou, J. Yang, G. Tang, X. Chen and F. Huang, Pillar[5]arene-based amphiphilic supramolecular brush copolymer: fabrication, controllable self-assembly and application in self-imaging targeted drug delivery, Polym. Chem., 40 (2016) 6178-6188.

[37] L. Jiang, X. Huang, D. Chen, H. Yan, X. Li and X. Du. Supramolecular vesicles coassembled from disulphide linked benzimidazolium amphiphiles and carboxylate substituted pillar[6]arenes that are responsive to five stimuli, Angrew. Chem. Int. Ed., 56 (2017) 2655-2659. 